\title{
化学新创实验的现状与发展对策
}

李厚金 ${ }^{1,}{ }^{*}$, 陈六平 ${ }^{1}$, 张树永 2

1 中山大学化学学院, 广州 510006

2 山东大学化学与化工学院, 济南 250100

摘要: 近年来, 化学实验教学改革取得很大成就。本文对当前国内高校的化学新创实验设计的现状进行了分析, 探讨了 未来新创实验的选题方向、创制途径、教学实施和评价方法，希望对同行有参考价值。

关键词: 化学实验; 创新; 现状; 对策

中图分类号: G64; O6-3

\section{Current Situation and Development Countermeasure of Chemical Innovation Experiments}

\author{
Houjin $\mathrm{Li}^{1}{ }^{1}{ }^{*}$, Liuping Chen ${ }^{1}$, Shuyong Zhang ${ }^{2}$ \\ ${ }^{1}$ School of Chemistry, Sun Yat-Sen University, Guangzhou 510006, China. \\ ${ }^{2}$ School of Chemistry and Chemical Engineering, Shandong University, Jinan 250100, China.
}

Abstract: In recent years, the reformation of chemical experiment teaching has made great achievements. The current situation of the design of the new chemical experiments is analyzed. The direction of topic selection, design method, teaching practice and evaluation of the new experiments in the future are discussed. This paper is expected to have reference value for peers.

Key Words: Chemical experiment; Innovation; Current situation; Countermeasures

化学是一门以实验为基础的学科, 化学实验能力是化学专业人才的核心竞争力。学生通过化学 实验不仅可以理解化学的原理和本质, 而且还能够牢固掌握规范、安全的实验操作技能, 提高科学 分析问题、解决问题的能力, 培养学生实事求是和严谨的科学态度, 在科学研究方法、创新能力上 得到系统的训练和提高, 同时激发和培养学生对化学的兴趣和热爱。

近年来, 各高校在化学实验基础条件建设方面取得了重要成就。实验室设计规范标准, 通风棏、 实验服、护目镜、手套、“三废” (废液、废气、固体废弃物)的回收处理, 提高了实验的安全性, 培 养了学生的安全环保及社会责任意识。众多的现代科学仪器已经应用于教学实验。小班化教学、精 细化指导提高了教学效果。当然, 目前我国高校化学实验教学依然存在不少问题: 教学体系、教学 理念、教学内容、教学方法、教学考核等仍未达到与硬件建设协调发展的应有水准 ${ }^{[1-3]}$; 出版的实验 教材很多, 但内容大同小异; 实验教学主要关注 “三基” (基础知识、基本理论、基本技能), 实验内 容陈旧单一、缺乏综合性和设计性, 教学要求不高, 挑战性差, “照方抓药” 式的教学难以培养学

收稿: 2021-08-05; 录用: 2021-09-07; 网络发表: 2021-10-25

“通讯作者, Email: ceslhj@mail.sysu.edu.cn

基金资助: 广东省高等教育教学改革项目; 中山大学教学改革研究项目 
生的探究能力和创新能力, 教学效果不理想。随着化学学科的飞速发展, 实验教学内容落后于时代 已成为一个突出的问题 ${ }^{[4,5]}$ 。

本文拟对当前国内化学新创实验设计的现状进行分析, 探讨新创实验的选题方向、创制途径、 教学实施和评价方法, 为同行提供参考。

\section{1 化学新创实验设计的现状}

新创实验是指将反映新知识、新理论、新技术、新方法等的最新成果设计为适合本科生的教学实 验。我们以2017年1月-2021年3月间在《大学化学》上发表的代表性新创实验(表1)以及2019年第一届 全国大学生化学实验创新设计竞赛获奖作品代表(表2)为例, 分析我国高校化学新创实验设计的现状。

\section{表1 2017年1月-2021年3月间在《大学化学》期刊发表的新创实验的主要选题方向}

\begin{tabular}{|c|c|c|c|c|}
\hline 序号 & 文章题目 & 期刊目录 & 实验类别 & 主要选题方向 \\
\hline \multirow[t]{2}{*}{1} & 碳点的合成及对锰离子的比色检测一一推荐一个大 & 2020,35 (12), 206-211. & 综合 & 纳米材料 \\
\hline & 学化学综合实验 & & & \\
\hline \multirow[t]{2}{*}{2} & 碳点的制备及苂光量子产率的测定一一个仪器分 & $2019,34(7), 67-72$. & 综合 & 纳米材料 \\
\hline & 析综合实验 & & & \\
\hline \multirow[t]{2}{*}{3} & 海藻酸盐微胶囊及纳米 $\mathrm{Fe}_{3} \mathrm{O}_{4}$ 的可控制备及应用的研 & $2020,35(2), 33-42$. & 综合 & 纳米材料、吸附作用 \\
\hline & 究一一绍一个综合探究实验 & & & \\
\hline \multirow[t]{2}{*}{4} & 纳米 $\mathrm{Fe}_{2} \mathrm{O}_{3}$ 和 $\mathrm{Fe}_{3} \mathrm{O}_{4}$ 的制备及其催化高氯酸铵热分解 & $2018,33(4), 51-56$. & 综合 & 纳米材料、催化反应 \\
\hline & 性能的研究—一个仪器分析综合实验 & & & \\
\hline \multirow[t]{2}{*}{5} & $\mathrm{TiO}_{2}$ 纳米粉体的掺杂改性及光催化性能研究一一伯苓 & $2020,35(2), 50-57$. & 综合 & 纳米材料、光催化作用 \\
\hline & 班无机综合实验 & & & \\
\hline \multirow[t]{2}{*}{6} & 氮氟双掺杂 $\mathrm{TiO}_{2}$ 纳米管的制备、表征和光催化性能研 & $2017,32(12), 60-68$. & 综合 & 纳米材料、光催化作用 \\
\hline & 究——暑期科研训练实验实例 & & & \\
\hline 7 & 基础实验：金纳米粒子的制备及其光学性质 & $2019,34(1), 58-63$. & 基础 & 纳米材料、探针效应 \\
\hline \multirow[t]{2}{*}{8} & $\mathrm{YVO}_{4}: \mathrm{Eu}$ 发光材料的合成、结构与菼光性一一推荐一 & $2018,33(10), 79-84$. & 综合 & 纳米材料、光致发光 \\
\hline & 个大学综合实验 & & & \\
\hline 9 & $\begin{array}{l}\text { 纳米比色法测定左氧氟沙星含量的仪器分析实验设 } \\
\text { 计 }\end{array}$ & $2017,32(12), 69-73$. & 仪器分析 & 纳米材料、药物分析 \\
\hline \multirow[t]{2}{*}{10} & $\mathrm{CuInS}_{2} / \mathrm{ZnS}$ 量子点的微波水热合成与表征一一推荐一 & $2017,32(11), 51-56$. & 综合 & 纳米材料 \\
\hline & 个研究型综合实验 & & & \\
\hline \multirow[t]{2}{*}{11} & 抗体与多酶负载纳米金的合成表征及纸上化学发光 & $2017,32(2), 69-73$. & 综合 & 纳米材料 \\
\hline & 性能研究一介绍一个仪器分析综合实验 & & & \\
\hline \multirow[t]{2}{*}{12} & 形貌各异 $\mathrm{ZnO}$ 微结构的合成与表征一一个简单有趣 & $2017,32(1), 48-51$. & 综合 & 纳米材料 \\
\hline & 的化学综合实验 & & & \\
\hline \multirow[t]{2}{*}{13} & SAB-16型介孔材料的制备、表征及表面改性一一介绍 & $2020,35(9), 126-131$. & 综合 & 功能材料、介孔材料、吸附作用 \\
\hline & 一个材料化学综合实验 & & & \\
\hline
\end{tabular}


(续表1)

\begin{tabular}{|c|c|c|c|c|}
\hline 序号 & 文章题目 & 期刊目录 & 实验类别 & 主要选题方向 \\
\hline 14 & $\begin{array}{l}\mathrm{ZnO}-\mathrm{g}-\mathrm{C}_{3} \mathrm{~N}_{4} \text { 多孔Z型异质结的合成及净化有机废水性 } \\
\text { 能研究一一推荐一个大学化学综合性实验 }\end{array}$ & $2020,35(9), 152-158$. & 综合 & $\begin{array}{l}\text { 功能材料、多孔Z型异质结、光 } \\
\text { 催化剂、吸附作用 }\end{array}$ \\
\hline 15 & $\begin{array}{l}\text { 多酸配位聚合物的制备与表征一推荐一个综合化 } \\
\text { 学实验 }\end{array}$ & $2020,35(1), 92-97$. & 综合 & 功能材料 \\
\hline 16 & $\begin{array}{l}\text { 二次生长法 } \mathrm{NaA} \text { 沸石分子篮膜的合成与表征一一推荐 } \\
\text { 一个研究型综合实验 }\end{array}$ & $2018,33(9), 69-74$. & 综合 & 功能材料、沸石分子篮膜 \\
\hline 17 & $\begin{array}{l}\text { 压电陶瓷传感器的制作及压电效应演示综合性实验 } \\
\text { 设计一一介绍一个材料化学综合实验 }\end{array}$ & $2017,32(4), 52-60$. & 综合 & 功能材料、压电陶瓷传感器 \\
\hline 18 & $\begin{array}{l}\text { 甲基橙插层水滑石的制备及表征—一个大学化学 } \\
\text { 开放性实验设计 }\end{array}$ & $2017,32(1), 52-57$. & 综合 & 功能材料、水滑石插层材料 \\
\hline 19 & $\begin{array}{l}\text { 聚苯胺-木质素磺酸复合物的合成及其染料吸附 } \\
\text { 性能一一介绍一个综合性研究型实验 }\end{array}$ & $2017,32(3), 49-54$. & 综合 & 功能高分子材料、吸附作用 \\
\hline 20 & $\begin{array}{l}\text { 温度响应高分子微凝胶的水相制备与表征一个绍 } \\
\text { 一个大学化学综合实验 }\end{array}$ & $2021,36(2), 1912023$. & 综合 & $\begin{array}{l}\text { 功能高分子材料、温度响应材 } \\
\text { 料、自由基聚合 }\end{array}$ \\
\hline 21 & $\begin{array}{l}\text { 聚乙烯吡咯烷酮聚合物复合膜的制备及其性能研 } \\
\text { 究——推荐一个研究型综合实验 }\end{array}$ & $2020,35(9), 120-125$. & 综合 & $\begin{array}{l}\text { 功能高分子材料、高温质子交换 } \\
\text { 膜 }\end{array}$ \\
\hline 22 & $\begin{array}{l}\text { 有机化学知识在高分子材料合成创新实验中的 } \\
\text { 运用一一分享几个实例 }\end{array}$ & $2020,35(7), 104-108$ & 综合 & 功能高分子材料 \\
\hline 23 & $\begin{array}{l}\text { 含苆共轭高分子的合成、表征及性能研究一一推荐一 } \\
\text { 个高分子化学综合实验 }\end{array}$ & $2018,33(8), 37-42$. & 综合 & $\begin{array}{l}\text { 功能高分子材料、光电材料、人 } \\
\text { 名反应、Sonogashira偶联反应 }\end{array}$ \\
\hline 24 & $\begin{array}{l}\text { 苯胺四聚体合成及电致变色器件制备—一个大学 } \\
\text { 化学综合性实验 }\end{array}$ & $2018,33(6), 38-44$. & 综合 & 功能高分子材料、导电高分子 \\
\hline 25 & $\begin{array}{l}\text { 新型电控苂光聚合物的合成与性能研究——推荐一 } \\
\text { 个综合化学实验 }\end{array}$ & $2019,34(3), 47-52$. & 综合 & 功能高分子材料、苂光材料 \\
\hline 26 & $\begin{array}{l}\text { 磁性 } \mathrm{Co} / \mathrm{C} \text { 纳米复合材料的合成及其对水中刚果红吸 } \\
\text { 附性能研究 }\end{array}$ & $2020,35(12), 212-220$. & 综合 & $\begin{array}{l}\text { 金属有机框架材料、纳米材料、 } \\
\text { 吸附作用 }\end{array}$ \\
\hline 27 & $\begin{array}{l}\text { 一种金属有机框架纳米材料的制备及其染料吸附性 } \\
\text { 能研究一一推荐一个研究型综合化学实验 }\end{array}$ & $2018,33(9), 75-81$. & 综合 & $\begin{array}{l}\text { 金属有机框架材料、纳米材料、 } \\
\text { 吸附作用 }\end{array}$ \\
\hline 28 & $\begin{array}{l}\text { 锌配位聚合物的制备与表征一推荐一个无机化学 } \\
\text { 综合实验 }\end{array}$ & $2017,32(5), 55-60$. & 综合 & 金属有机框架材料、吸附作用 \\
\hline 29 & $\begin{array}{l}\text { 一种基于智能手机可视化多色荧光检测碱性磷酸酶 } \\
\text { 活性的方法一一推荐一个本科生科研训练项目 }\end{array}$ & $2020,35(6): 110-116$. & 本科科研 & 金属有机框架材料、苂光检测 \\
\hline 30 & $\begin{array}{l}\text { 四苯乙烯的合成、表征及在爆炸物检测中的应用一 } \\
\text { 介绍一个大学化学综合实验 }\end{array}$ & $2019,34(1), 48-53$. & 综合 & $\begin{array}{l}\text { 聚集诱导发光、人名反应、 } \\
\text { McMurry偶联反应、苂光检测 }\end{array}$ \\
\hline
\end{tabular}




\begin{tabular}{|c|c|c|c|c|}
\hline 序号 & 文章题目 & 期刊目录 & 实验类别 & 主要选题方向 \\
\hline 31 & $\begin{array}{l}\text { 席夫碱型有机小分子菼光探针的制备与表征——推 } \\
\text { 荐一个综合化学实验 }\end{array}$ & $2020,35(2), 70-74$. & 综合 & 苂光探针 \\
\hline 32 & $\begin{array}{l}\text { BODIPY基荧光探针的合成、表征及对铜离子的 } \\
\text { 检测一一推荐一个大学综合化学实验 }\end{array}$ & $2017,32(11), 57-64$ & 综合 & 苂光探针 \\
\hline 33 & $\begin{array}{l}\text { 聚苯胺薄膜在电量可视化超级电容器中的应用一 } \\
\text { 推荐一个综合化学实验 }\end{array}$ & 2021, 36 (2), 2003007. & 综合 & 导电聚合物、超级电容器 \\
\hline 34 & $\begin{array}{l}\text { 设计综合性实验强化物理化学理论课教学探索— } \\
\text { 以原电池设计为例 }\end{array}$ & 2021, $36(1), 1910051$. & 综合 & 原电池 \\
\hline 35 & $\begin{array}{l}\text { 杂化钙钓矿光伏材料的合成及热稳定性研究—推 } \\
\text { 荐一个综合化学实验 }\end{array}$ & $2020,35(1), 59-63$. & 综合 & 钻钛矿太阳能电池 \\
\hline 36 & $\begin{array}{l}\text { 天然染料敏化太阳能电池的制备—一个大学化学 } \\
\text { 综合性实验 }\end{array}$ & $2017,32(6), 75-81$. & 综合 & 染料敏化太阳能电池 \\
\hline 37 & $\begin{array}{l}\text { 手性有机小分子催化剂 } 6,7-二 \text { 二氢- }-5 H \text {-吡咯并 }[1,2-a] \text { 咪 } \\
\text { 唑的合成一介绍一个大学有机化学综合实验 }\end{array}$ & $2019,34(4), 55-60$. & 综合 & 手性有机小分子催化剂 \\
\hline 38 & $\begin{array}{l}\text { HZSM-5 分子篮催化合成乙酰水杨酸一推荐一个半 } \\
\text { 微量有机化学实验 }\end{array}$ & $2018,33(8), 43-46$. & 有机 & 催化反应、绿色化学 \\
\hline 39 & $\begin{array}{l}\text { 铜卟啉合成及其敏化二氧化钣光催化剂的制备— } \\
\text { 一个大学化学综合性实验 }\end{array}$ & $2017,32(4), 46-51$. & 综合 & 光催化剂 \\
\hline 40 & $\begin{array}{l}\text { 嵌碳 } \mathrm{TiO}_{2} \text { 的快速制备及其光催化制氢特性一一绍一 } \\
\text { 个材料综合实验 }\end{array}$ & $2017,32(2), 63-68$. & 综合 & 光催化剂 \\
\hline 41 & 催化苂光法测定痕量铜的探究性实验设计与实践 & $2017,32(1), 58-61$. & 探究性 & 催化动力学苂光分析法 \\
\hline 42 & $\begin{array}{l}\text { 诺贝尔化学奖类大学生创新实验—Suzuki偶联反应 } \\
\text { 制备DPP类荧光染料 }\end{array}$ & 2020,35 (12), 227-232. & 综合 & 人名反应、Suzuki偶联反应 \\
\hline 43 & $\begin{array}{l}\text { 8-羟基喹啉及其铝配合物的合成、表征及发光性能- } \\
\text { 推荐一个综合化学实验 }\end{array}$ & 2017,32 (12), 53-59. & 综合 & 人名反应、Skraup合成法 \\
\hline 44 & $\begin{array}{l}\left.4^{\prime} \text {-\{2-[5-(4-羧基苯基)呋喃基] }\right\} \text { - } 2,2^{\prime}: 6^{\prime}, 2^{\prime}{ }^{\prime} \text {-三联吡啶 } \\
\text { 的合成一一推荐一个大学有机化学实验 }\end{array}$ & $2017,32(6), 82-85$ & 综合 & $\begin{array}{l}\text { 人名反应、Michael加成、芳环偶 } \\
\text { 联、 } \alpha, \beta \text {-不饱和酮合成 }\end{array}$ \\
\hline 45 & $\begin{array}{l}\text { 微通道反应器中连续化合成苯亚甲基丙酮一介绍 } \\
\text { 一个大学化学综合实验 }\end{array}$ & $2019,34(5), 51-56$. & 综合 & 微反应技术 \\
\hline 46 & $\begin{array}{l}\text { 板蓝根中提取靛蓝应用于扎染的创新实验教学— } \\
\text { 介绍一个大学化学综合教学实验 }\end{array}$ & $2020,35(9), 148-151$. & 综合 & 天然产物化学 \\
\hline 47 & $\begin{array}{l}\text { 构树叶中黄酮类化合物的提取及测定一一介绍一个 } \\
\text { 大学综合化学实验 }\end{array}$ & $2018,33(12), 67-70$ & 综合 & 天然产物化学 \\
\hline 48 & $\begin{array}{l}\text { 芦丁的提取鉴定及不同剂型与体内释放相关性的研 } \\
\text { 究—一制药工程相关专业综合创新实验设计 }\end{array}$ & $2017,32(10), 39-46$. & 综合 & 天然产物化学 \\
\hline
\end{tabular}


表2 2019年第一届全国大学生化学实验创新设计竞赛获奖的新创实验作品的主要选题方向

\begin{tabular}{|c|c|c|}
\hline 序号 & 作品名称 & 主要选题方向 \\
\hline 1 & 联二炔囊泡的光致聚合、热致变色及应用 & 纳米材料、光致聚合、热致变色 \\
\hline 2 & 半导体纳米复合材料的制备及其光电催化 $\mathrm{CO}_{2}$ 还原 & 纳米材料、光电催化 \\
\hline 3 & 基于氢键作用的金纳米粒子比色法检测尿酸 & 纳米材料、纳米分析 \\
\hline 4 & 铋离子选择性电极的制备及测定胃药中的 $\mathrm{Bi}^{3+}$ 含量 & 纳米材料、电化学传感器、电位分析法 \\
\hline 5 & 薄膜导电材料的制备及催化性能研究 & 纳米薄膜导电材料、催化反应 \\
\hline 6 & 疏水性硼酸镁的制备及测试 & 纳米材料表面改性 \\
\hline 7 & 物理化学综合实验 - $\mathrm{CdS}$ 的制备、表征及光催化分解水制氢 & 纳米材料、光催化反应 \\
\hline 8 & 组氨酸修饰苂光金纳米团簇的光稳定性探究 & 纳米材料、苂光探针 \\
\hline 9 & 会变形的水凝胶 & 功能高分子材料、水凝胶 \\
\hline 10 & 废旧棉中纤维素的提取改性及水凝胶的制备 & 功能高分子材料、水凝胶、绿色化学 \\
\hline 11 & 聚醋酸乙烯酯的光引发可控合成 & 功能高分子材料、光引发聚合反应 \\
\hline 12 & 可变色形状记忆材料 & 功能高分子材料、水凝胶、热致变色 \\
\hline 13 & 电聚合制备分子印迹电极及其特异性表征 & 功能高分子材料、分子印迹电极 \\
\hline 14 & 一种锌基MOF材料的合成及苂光性能 & 金属有机框架材料、荧光探针 \\
\hline 15 & AIE苂光聚合物RAFT可控合成与表征及光物理性质研究 & 聚集诱导发光、无水无氧反应 \\
\hline 16 & 利用聚集诱导发光(AIE)现象观察分子定向运动的综合实验 & 聚集诱导发光、分子机器 \\
\hline 17 & 稀土一嘧啶羧酸配合物的合成、结构和发光性质 & 无机苂光材料 \\
\hline 18 & 适于暖白光LED用红色发光材料 $\mathrm{K}_{2} \mathrm{GeF}_{6}: \mathrm{Mn}$ 的合成 & 无机苂光材料 \\
\hline 19 & 永离子近红外荧光探针的合成及其可视化检测 & 荧光探针 \\
\hline 20 & 香豆素羟胺在糠醛类化合物苂光定量分析中的应用 & 苂光定量分析 \\
\hline 21 & 基于嘌呤的巯基二齿钻钛矿针化剂的合成及光伏应用 & 钙钛矿太阳能电池 \\
\hline 22 & 基于绿色化学理念的苯甲醛与安息香的相互转化 & 催化反应、绿色化学 \\
\hline 23 & 脂肪酶Novozym 435催化合成单月桂酸甘油酯 & 生物酶催化反应 \\
\hline 24 & 可见光源、绿色实验—LED光诱导下3-氧甲基化咪唑并吡啶类化合物的制备 & 光催化反应、绿色化学 \\
\hline 25 & 太阳能驱动 $\mathrm{Ni}-\mathrm{N}$ 掺杂多孔碳高效电催化还原 $\mathrm{CO}_{2}$ 为 $\mathrm{CO}$ & 电催化反应 \\
\hline 26 & 一氯二茂钛和路易斯酸协同催化芐醇脱羟基偶联反应 & 催化反应、无水无氧反应 \\
\hline 27 & $\mathrm{KF} / \mathrm{La}_{2} \mathrm{O}_{2} \mathrm{CO}_{3}$ 固体碱的制备、表征及催化酯交换反应的性能 & 催化反应 \\
\hline 28 & 导向基团辅助的铜催化 $\mathrm{C}-\mathrm{H}$ 键的酰氧化反应 & 催化反应、绿色化学 \\
\hline 29 & 氧化/酸双重活性中心多酸非均相催化剂的设计及催化玉米秸秆多级转化 & 催化反应、绿色化学 \\
\hline 30 & 基于铜介导的 $[5+1]$ 环化反应合成取代喹啉衍生物 & 催化反应、绿色化学 \\
\hline 31 & $N$-炔丙基-9-葱甲酰胺的一锅法合成及其分子内环化反应 & 催化反应、一锅法反应 \\
\hline 32 & 酒石酸氧化反应中催化剂的作用 & 催化反应 \\
\hline 33 & Ugi四组分一锅法高效合成结构独特的活性生物碱化合物 & $\begin{array}{l}\text { 人名反应、Ugi反应、多组分反应、一锅法反 } \\
\text { 应、绿色化学 }\end{array}$ \\
\hline 34 & 一种新型有机质子响应苂光分子的合成在实验教学中的设计与探索 & 人名反应、Knoevenagel反应、聚集诱导发光 \\
\hline 35 & 化学发光促进的噻吩 $\mathrm{C}-\mathrm{H}$ 键芳基化反应 & $\begin{array}{l}\text { 人名反应、Sonogashira偶联反应、光催化 } \\
\text { 反应、无水无氧反应 }\end{array}$ \\
\hline 36 & $\beta$-氨基酸酯类衍生物的合成及拆分 & $\begin{array}{l}\text { 人名反应、Mannich反应、一锅法反应、手性 } \\
\text { 拆分 }\end{array}$ \\
\hline
\end{tabular}




\begin{tabular}{cll}
\hline 序号 & \multicolumn{1}{c}{ 作品名称 } & 主要选题方向 \\
\hline 37 & 一个微量不对称合成教学实验—手性高烯丙基胺的高效合成及表征 & 无水无氧反应、不对称合成、微量反应 \\
38 & 文旦柚皮中黄酮的提取鉴定及抗氧化性研究 & 天然产物化学 \\
39 & 纸基显色传感器用于白酒中硫离子含量测定的研究 & 绿色化学 \\
40 & $(Z)-2$-(唒唑烷-2-亚基)-3,3,3-三氟丙酸甲酯的合成 & 绿色化学、氟化学 \\
41 & 三乙胺/水杨酸新型低温共熔溶剂的合成、表征与性能 & 绿色化学、低温共熔溶剂 \\
\hline
\end{tabular}

2017年1月-2021年3月, 《大学化学》共发表新创实验63个(不包括全国大学生化学实验创新设计 竞赛特刊的 20 篇), 其中综合实验 52 个, 占比 $82.5 \%$ 。2019年第一届全国大学生化学实验创新设计竞 赛获奖作品共 65 项, 其中新创实验 46 项, 改进实验 13 项, 科普实验 6 项 ${ }^{[6]}$ 。新创实验以综合实验为主, 内容有一定难度, 实验过程具有探究性, 有利于培养学生解决复杂问题的综合能力和高级思维。

科教融合是当前教育改革的热点。《国家中长期教育改革和发展规划纲要(2010-2020年)》明确指 出: “支持学生参与科学研究, 强化实践教学环节” “促进科研与教学互动、与创新人才培养相结 合” 。《教育部关于加快建设高水平本科教育 全面提高人才培养能力的意见》也强调 “将最新科研 成果及时转化为教育教学内容, 以高水平科学研究支撑高质量本科人才培养”。表 1 和表 2 显示, 新 创实验的选题热点有纳米材料、功能高分子材料、金属有机框架材料、聚集诱导发光、新型电池、 苂光探针、催化剂的制备和应用、人名反应、一锅法反应、绿色化学、天然产物化学等, 有部分新 创实验同时涵盖多个方向。新创实验的选题方向与中国科学院科技战略咨询研究院、中国科学院文 献情报中心与科睿唯安联合发布的《研究前沿》和《研究前沿热度指数》年度报告 (http://www.casisd.cn/zkcg/zxcg/) 高度吻合, 说明大部分指导教师能够指导学生将最新科研项目改编 成教学实验, 使新创实验能够紧跟学科发展前沿, 实现科研成果向教学实验的转化。

\section{2 化学新创实验的发展与对策}

目前, 化学新创实验设计取得一定成就, 但已编入了实验教材或实际应用于教学的项目占比仍 然比较低。新创实验的未来发展, 仍需要重点解决以下几个方面:

(1) 开发贴近实际、“接地气” 的实验教学内容。新创实验内容要在体现新颖性, 将化学新方法、 新原理、新物质、新功能引入实验教学的同时, 增加应用型实验, 解决实验内容 “顶天” 多, “立地” 少的问题。特别是对于农、林、医、工、师范类以及一些地方性高校, 不要盲目在国际顶尖科技成 果或者热点领域中去寻找开发新实验项目, 而是应该根据各自学校的学科特点、地方资源和行业特 色、学生未来就业与发展的需要, 开发系列贴近实际、“接地气” 的实验教学内容, 在提高实验新颖 性的同时注重实用性和趣味性, 这对提高实验教学效果大有裨益。

(2) 兼顾实验教学的可行性。不少新创实验在设计时重点考虑了创新性和前沿性, 但对是否适 合本科教学考虑不多; 很多新创实验盲目追求使用现代分析表征手段, 看似高大上, 实际上导致实 验的可操作性变差。新创实验项目的核心价值在于其推广应用和教学效果, 是否适合作为本科实验 是创制实验项目必须优先考虑的因素。例如, 有机化学实验选题范围可以很广, 如不对称合成、催 化反应、微量反应、绿色合成、无水无氧反应、人名反应、诺贝尔化学奖反应、药物合成、天然产 物化学实验等, 但是否适合作为教学实验则需要考虑: (1) 实验时长。实验以 $4-6 \mathrm{~h}$ 完成为宜。对于长 时间实验, 最好能够合理划分为 $2-4$ 个时段, 每个时段不要超过 $6 h$; (2) 实验仪器设备。实验仪器不 能太贵重, 避免大量和非必要使用大型仪器设备, 否则难以推广; (3) 实验试剂的价格和安全性。试 剂最好价廉易得, 宜安全绿色, 不宜有毒有害; (4) 实验操作安全性好。不宜选用易燃、易爆的危险 性实验; 实验最好采用常规条件, 避免超低温、高温、高压、严格无水无氧等操作; (5) 实验现象明 显。实验步骤不宜太多, 产率不宜太低, 实验稳定, 结果重现性好。要努力践行绿色、环保、安全 
的实验教育理念, 树立新时代化学实验的新形象。

(3) 突出科研育人。新创实验是落实科教融合的重要途径。通过巧妙的实验设计, 把最新的前沿 科学研究成果编入教材、引入实验课堂, 通过拓展实验的背景知识, 通过综合多学科、多种实验技 术设置真实的问题情境, 激发学生探索未知世界的好奇心, 并通过参与科研过程将所学知识与能力 培养融会贯通, 全面提升素质和能力, 使学生的创新意识不断加强, 科研方法逐渐规范, 自主学习 能力、研究能力、沟通协作能力不断增强, 是将科研成果引入本科实验的初衷。另外, 改变 “照方 抓药” 的传统实验教学模式, 在新创实验中采取团队合作的实验方式, 通过多参数设置, 引导学生 积极探究, 增强分析和综合能力, 采用研究型教学模式, 才能真正发挥新创实验的作用, 提升实验 教学创新性、高阶性和挑战度。目前, 很多新创实验在引入新原理、新方法、新体系的同时, 却采 用了传统型实验教学模式, 其效果无疑会大打折扣, 无法实现新创实验的初衷。

(4) 深入挖掘课程思政内涵。实验教学的宗旨是落实立德树人根本任务, 要以学生为中心, 促进 学生的全面健康成长。依托科研最新成果开设的新创实验, 能更多地体现科研思维方式、社会责任、 担当精神、创新意识和绿色发展意识等, 具有较传统实验更加丰富的课程思政内涵。因此, 新创实 验要更加自觉地推进 “思政育人”, 引导学生树立远大的理想和正确的价值观, 坚持科学精神, 严 守学术规范, 遵循科学伦理, 担当社会责任。

(5) 合理调控新创实验方向。实验教学体系是一个以人才培养目标为导向的科学体系, 每个实 验都担负着培养学生独特的知识、能力和素质的使命。只有合理融入实验教学体系, 新创实验才能 发挥其应有的效能。目前, 绝大多数新创实验仅仅是单个的、独立的实验, 并未被纳入实验教学体

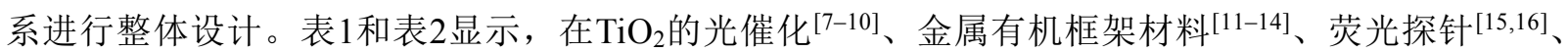
聚集诱导发光 ${ }^{[17-19]}$ 等新兴的热点科研方向上开发的实验项目数量比较多, 这虽然是当前科研热点和 人才培养需求的合理反映, 但一味地追逐热点, 开发过多的类似实验项目, 最终很难得到应用推 广，这也会成为一种资源浪费。

(6) 完善效果评价。新创实验大多是综合性、设计型实验, 是化学实验教学的较高层次, 对学生 综合素质和创新能力有着更高的要求。学生为了完成实验, 可能需要阅读大量文献, 拓展相关研究 的背景知识; 在实验过程中往往需要教师更多的指导和同学间的相互协作; 实验完成后可能需要小 组讨论, 一起分享实验的经验、体会和感想, 即具有更显著的过程性特征。因此, 传统的实验考核 评价体系对这些新创实验并不适合。建立综合过程性、终结性考核的实验教学效果评价机制, 对学 生在文献研读、实验设计、实验操作、问题分析、总结提升、过程反思等方面进行全过程评测, 建 立全面、客观、准确、严谨的考核体系, 以目标为导向, 通过考核充分调动学生学习的能动性, 提 升学生的参与度, 也是新创实验需要重点考虑的问题。

\section{3 结语}

近年来, 符合化学学科发展潮流, 融入了新知识、新理论、新技术、新方法的新创实验项目大 量涌现, 为化学实验教学带来了勃勃生机。与此同时, 新创实验在选题方向上一味追逐热点科研领 域, 不注重开发贴近实际、“接地气” 的实验教学内容, 提高实验实用性和趣味性的问题普遍存在。 在新创实验创制时, 应根据实验教学的特点, 综合考虑多方因素, 兼顾实验的安全性、可操作性和 可推广性。要精心设计教学过程, 拓展实验的背景知识, 融入课程思政, 创新教学方法, 提升实验 的趣味性, 使学生在实验方法、理论思考、实验过程体验、实验结果的综合分析等方面获得更全面、 更系统、更深入的训练, 促进综合能力提升。效果考核要更加关注学生创新思维和创新能力的培养, 引导他们由过去的 “学习、考试”型向 “学习、思考、研究、创新” 型转变。

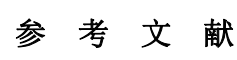

[1] 张树永, 朱亚先, 张剑荣. 大学化学, 2018, 33 (10), 1. 
[2] 张树永, 张剑荣, 陈六平. 大学化学, 2016, 31 (9), 1 .

[3] 李厚金, 陈六平. 大学化学, 2018, 33 (1), 7.

[4] 李厚金, 赖瑢, 朱可佳, 张利, 陈六平. 大学化学, 2017, 32 (4), 21.

[5] 李厚金, 陈六平. 大学化学, 2018, 33(10), 13.

[6] 张剑荣: 第一届全国大学生化学创新实验设计竟赛总结. [2021-08-05]. https://cid.nju.edu.cn/redirectActionxwgl/detail/45

[7] 朱宝林, 张沙沙, 霍国钠, 马露露, 李振宁, 赵榛翔, 申启捷, 邱晓航. 大学化学, 2020, 35 (2), 50.

[8] 朱宝林, 马露露, 王雪, 邱晓航. 大学化学, 2017, 32 (12), 60.

[9] 南志祥, 李珺, 张逢星, 白银娟. 大学化学, 2017, 32 (4), 46.

[10] 李乔丹, 马晓清, 崔晓莉. 大学化学, 2017, 32 (2), 63.

[11] 秦雨欣, 林天然, 李金荣, 覃思媛, 侯丽. 大学化学, 2020, 35 (6), 110 .

[12] 乔正平, 尹明大, 许先芳, 黄华珍, 间素君, 彭慧娟, 毛宗万. 大学化学, 2018, 33 (9), 75.

[13] 余凡, 李艾华, 张玉敏, 邹新, 胡思前. 大学化学, 2017, 32 (5), 55 .

[14] 蔡丹丹, 阮长平, 邱建华, 吴丽芸, 张丛, 张羽真. 大学化学, 2020, 35 (12), 212.

[15] 孙长艳, 李文军, 陆慧丽. 大学化学, 2020, 35 (2), 70 .

[16] 何田, 顾峥烨, 曾雨霏, 胡余宗, 尹守春. 大学化学, 2017, 32 (11), 57.

[17] 何田, 顾峥烨, 尹守春. 大学化学, 2019, 34 (1), 48.

[18] 李嘉梁, 汪博宇, 付薪宇, 宋志光, 朱万春, 范勇, 马强, 郭玉鹏. 大学化学, 2020, 35 (4), 60.

[19] 刘天瑞, 赵伟光, 张妍欣, 冯凯旋, 徐天驰, 章文伟, 谌东中. 大学化学, 2020, 35 (4), 81. 